\title{
Validity of Self-Reported Body Mass Index and Sleeping Problems Among Adult Population of Georgia
}

\author{
Jin-Mann S. Lin ${ }^{*}$, Michael J. Decker, Dana J. Brimmer and William C. Reeves
}

Chronic Viral Diseases Branch, Mail Stop A-15, National Center for Zoonotic, Vector-borne and Enteric Diseases,
Centers for Disease Control and Prevention, Atlanta, GA, USA

\begin{abstract}
Purpose: This study assessed the validity of body mass index (BMI) derived from self-reported height and weight in comparison to BMI derived from clinical measurement. We further examined the misclassification effect of self-reported BMI in association with complaints of snoring and excessive daytime sleepiness.
\end{abstract}

Methods: Data came from a population-based study of chronic fatigue syndrome (CFS) and unwellness, between September 2004 and July 2005, in metropolitan, urban, and rural Georgia. We compared self-reported with clinicallymeasured height and weight from 774 persons aged 18-59 and the bias impact on their association with snoring and excessive daytime sleepiness.

Results: The correlation coefficient between self-reported and clinically-measured BMI was $0.92(\mathrm{p}<0.0001)$ and intraclass correlation coefficient was 0.90 . For overweight persons (BMI $>=25 \mathrm{~kg} / \mathrm{m}^{2}$ ), self-reported BMI had $89 \%$ sensitivity and $95 \%$ specificity compared to clinically-measured BMI. Misclassification of self-reported BMI categories revealed slightly higher odds ratios (ORs) for obese categories in predicting the likelihood of having a snoring problem than those based on measured values.

Conclusions: Self-reported height and weight are valid for determining BMI categories and the relationship to snoring in a large-scale population study.

Keywords: Body mass index (BMI), self-reported data, snoring, excessive daytime sleepiness, misclassification, intra-class correlation.

\section{INTRODUCTION}

The prevalence of overweight and obesity has increased worldwide during the past 30 years [1] and coincides with an increased prevalence of sleep disorders such as sleep apnea [2]. There are two common correlates of sleep apnea. Snoring correlates with sleep apnea, increasing up to late middle age and decreasing thereafter; obesity is the other major correlate of sleep apnea [2]. Various studies have found the prevalence of snoring in the adult population ranges from $5 \%$ to $59 \%$ [2-8]. Snoring and increased upper airway resistance are recognized precursors for impaired academic and professional performance, as well as increased morbidity and mortality [9-11]. In addition to correlating with sleep apnea, several population-based studies have shown an association of obesity with snoring and daytime sleepiness. A study from Shanghai demonstrates that snoring is positively correlated with body mass index (BMI), independent of menstrual status, in women [12]. Additionally, Bixler and colleagues show that excessive daytime sleepiness (EDS) is strongly associated with BMI [13]. In both studies, BMI was calculated from self-reported height and weight.

Self-reported data are a cost-effective way of obtaining information such as BMI and behavioral and lifestyle factors

*Address correspondence to this author at the Chronic Viral Diseases Branch, Centers for Disease Control and Prevention, Mail Stop A-15, Atlanta, GA 30333, USA; Tel: 404-639-1646; Fax: 404-639-2779; E-mail: dwe3@cdc.gov in large epidemiologic population-based studies. However, there is debate about the validity of "self-reported" BMI as calculated from self-reported height and weight. In a recent systematic review, Connor et al. demonstrated that selfreported data typically result in underestimating weight, overestimating height and significant misclassification of BMI categories [14]. The misclassification of self-reported BMI categories obscured the association between obesity and health conditions such as asthma [15], diabetes [16], high blood pressure [17], and heart disease [18]. On the contrary, using disease biomarkers (i.e. systolic blood pressure, fasting blood levels of glucose, high-density lipoproteincholesterol, triglycerides, C-reactive protein, and leptin), McAdams et al. [17] showed that the accuracy of selfreported BMI is sufficient for epidemiological studies.

Efforts to evaluate the misclassification effect of selfreported BMI categories in association with sleep are limited. In this study, we assessed the validity of selfreported BMI obtained during a Computer Aided Telephone Interview (CATI) with BMI obtained during a follow-up clinical examination. We further examined the misclassification effect of self-reported BMI categories in association with snoring and excessive daytime sleepiness.

\section{METHODS}

This study was reviewed and approved by the CDC Institutional Review Board, as required by the Department of 
Health and Human Services. All participants provided informed consent.

\section{Overview of Study Design}

Data came from a large-scale study of chronic fatigue syndrome (CFS) in metropolitan, urban, and rural Georgia [7, 19]. Between September 2004 and July 2005 we used random-digit-dialing to contact 10,837 households and queried the household informant concerning the health status of the 19,381 residents. We then conducted detailed telephone interviews with 5,623 of those residents who had been identified as unwell or as well. Based on the health and health-related information from the detailed phone interviews, subjects were classified three groups:

1. CFS-like - characterized by severe fatigue lasting six months or longer that was not alleviated by rest; caused substantial reduction in occupational, educational, social, or personal activities; and accompanied by at least four of the CFS case-defining symptoms [20].

2. Chronically unwell - having chronic ( $\geq$ six months) unwellness with or without fatigue, but not meeting the criteria for CFS-like.

3. Well - does not meet the criteria for CFS-like or chronically unwell, because all measurements fall in the normal range.

We invited all persons in the CFS-like group to participate in the one-day clinical evaluation. We also invited a random selection of persons in the chronically unwell group. Finally, we randomly selected well respondents from the telephone interviews to participate in the clinic and matched these persons on age, sex, race, and geographic stratum to persons with CFS-like illness. Forty-eight percent (783) of invited subjects participated in the clinical evaluation.

\section{Measurements}

\section{Demographics}

Age, sex, race, residential area, and education were selfreported in the detailed phone interviews and further confirmed at the clinical evaluation.

\section{Body Mass Index (BMI)}

Self-reported weight and height were obtained during the CATI. Participants were specifically asked, "How tall are you?" and "How much do you weigh?" Responses for height were recorded in feet and inches and weight was recorded in pounds. These were later converted into metric units. Clinical measurements of height and weight were measured by a research nurse upon participants' arrival at the clinic. Height was measured in feet and inches, to the nearest quarter-inch. Weight was measured to the nearest pound, using a mechanical weight scale with participants in their street clothes (without shoes, hats, or coats). The values were converted into metric units. We computed BMI, from self-reports and clinic measurements, as the ratio of the weight in kilograms to height in meters squared $\left(\mathrm{kg} / \mathrm{m}^{2}\right)$. We estimated bias of self-reported body measurement as the difference between "self-reported" and "clinically measured" BMI. We further classified the continuous BMI into the categorical BMI groups: underweight $(\mathrm{BMI}<18.5)$, normal weight $(\mathrm{BMI}=$ 18.5-24.9), overweight (BMI= 25-29.9), obese class I (BMI= 30.0-34.9), and obese class II (BMI=35-39.9).

\section{Sleep Problems}

The sleep problems of interest were snoring and excessive daytime sleepiness. Snorers were identified as those who answered "Yes" to the question, "Do you know, or have you ever been told, that you snore loudly during sleep?" We used the Epworth Sleepiness Scale (ESS) to determine the level of daytime sleepiness [21]. The questionnaire asked the subject to rate his or her probability of dozing off or falling asleep on a scale of increasing probability from 0 to 3 in eight different situations, in contrast to feeling just tired. The scores for the eight questions were added to obtain a single number. A score of 10 or more was considered excessive daytime sleepiness.

\section{Statistical Analysis}

We reported summary statistics for bias of self-reported weight, height, and BMI by the demographic variables of age, sex, race, residential area, and education. Pearson correlation and intra-class correlation coefficients were employed to determine the reliability of self-reported and clinicallymeasured BMI. The sensitivity, specificity, positive predictive value, negative predictive value, and Kappa coefficient were used to determine the validity of the prevalence of overweight (BMI $>=25 \mathrm{~kg} / \mathrm{m}^{2}$ ) using self-reported BMI. We performed a multivariate linear regression analysis to examine the bias effect of self-reported BMI (continuous) on snoring and EDS. A multivariate logistic regression with the adjustment of demographic variables was performed to examine the misclassification effect of BMI categories on the risk of having sleep problems. Statistical analyses were performed using SAS Version 9.1 (SAS Institute; Cary, NC). Significance levels were set at 0.05 for two-sided tests.

\section{RESULTS}

Nine of the 783 clinic participants had not reported their weight during the telephone interview. Thus, this report concerns the 774 persons with both self-reported and measured heights and weights. The majority of participants were age 40 or older $(69 \%)$, female $(76 \%)$, white $(71 \%)$, welleducated ( $75 \%$ some college or above), and lived in the urban or rural areas $(83 \%)$ (Table 1$)$.

\section{Validity of Self-Reported BMI}

Weight and height reported by participants were significantly correlated with their measured values (weight: $r=0.95$; height: $\mathrm{r}=0.96 ; \mathrm{p}<0.0001)$. The correlation coefficient between self-reported and measured BMI was $0.92(\mathrm{p}<0.0001)$ and their intra-class correlation coefficient was $0.90(95 \%$ $\mathrm{CI}=0.89-0.91$ ). The difference between BMI derived by self-reported height and weight with that measured during the clinical evaluation was not significantly correlated with the duration of time lapse between measurements (Pearson correlation $\mathrm{r}=0.02, \mathrm{p}=0.57$ ). Among 140 subjects who had less than a 60-day time elapse between the phone survey (self-reported) and the clinical evaluation (measured), the 
Table 1. Bias ${ }^{\mathrm{a}}$ of Self-Reported Height, Weight, and BMI by Demographic Variables

\begin{tabular}{|c|c|c|c|c|}
\hline & \multicolumn{4}{|c|}{ Bias } \\
\hline All & 774 & $0.02(1.06)^{b}$ & $-6.33(12.07)$ & $-1.06(2.09)$ \\
\hline \multicolumn{5}{|l|}{ Age } \\
\hline $18-29$ & $94(12.1)$ & $0.02(1.22)$ & $-5.34(11.49)$ & $-0.86(2.07)$ \\
\hline $50-59$ & $257(33.2)$ & $0.16(0.97)$ & $-5.01(10.32)$ & $-0.97(1.68)$ \\
\hline \multicolumn{5}{|l|}{ Sex } \\
\hline Female & $588(76.0)$ & $-0.07(0.91)$ & $-7.53(12.33)$ & $-1.21(2.16)$ \\
\hline Male & $186(24.0)$ & $0.32(1.40)$ & $-2.54(10.36)$ & $-0.60(1.78)$ \\
\hline Black & $193(24.9)$ & $0.03(1.16)$ & $-7.36(15.69)$ & $-1.24(2.63)$ \\
\hline All Other & $35(4.5)$ & $0.08(0.94)$ & $-5.21(9.99)$ & $-0.89(1.74)$ \\
\hline \multicolumn{5}{|l|}{ Residential Area } \\
\hline Metropolitan & $128(16.5)$ & $0.07(0.96)$ & $-5.22(9.82)$ & $-0.92(1.68)$ \\
\hline Urban & $265(34.2)$ & $0.00(1.00)$ & $-6.96(14.54)$ & $-1.15(2.41)$ \\
\hline Rural & $381(49.2)$ & $0.02(1.13)$ & $-6.27(10.80)$ & $-1.04(1.97)$ \\
\hline \multicolumn{5}{|l|}{ Education } \\
\hline$<$ High School & $45(5.8)$ & $0.15(1.22)$ & $-6.23(18.96)$ & $-1.16(3.08)$ \\
\hline
\end{tabular}

${ }^{\mathrm{a}}$ Bias of self-reported height $=$ self-reported height - measured height.

${ }^{b}$ Values are mean bias (standard deviation of bias).

duration of time elapse was also not significantly correlated with differences between self-reported and clinicallymeasured BMI ( $\mathrm{r}=0.02, \mathrm{p}=0.56)$. The self-reported BMI to detect overweight $\left(>=25 \mathrm{~kg} / \mathrm{m}^{2}\right)$ had a sensitivity of $89 \%$ (95\% exact binomial $\mathrm{CI}=87 \%-92 \%$ ), a specificity of $95 \%$ (95\% exact binomial CI $=92 \%$ - 98\%), a positive predictive value of $98 \%(95 \%$ exact binomial $\mathrm{CI}=96 \%-99 \%)$, and a negative predictive value of $81 \%$ (95\% exact binomial $\mathrm{CI}=$ $76 \%-85 \%)$. The Kappa coefficient was $0.81(95 \% \mathrm{CI}=0.76$ $-0.85)$.

\section{Bias Impact of Self-Reported BMI on its Association with Sleep Problems}

Table 1 also presents the differences between selfreported and clinically-measured weight and height and their derived BMI. On average, participants under-reported their weight by $6.33 \mathrm{lb}$, over-reported their height by 0.02 inches and so, under-reported their BMI by $1.06 \mathrm{~kg} / \mathrm{m}^{2}$. Underestimation of BMI was considerably greater for women than men. However, this difference was not influenced by age, race, residence, or education. The overall prevalence of overweight was $68 \%$ when it was calculated from measured BMI at the clinic, compared to the $62 \%$ prevalence of overweight calculated from self-reported BMI at the phone interview (data statistics not shown in tables).
Table 2 presents the associations (unadjusted and adjusted coefficient $\beta$ ) between the bias of self-reported BMI (derived from self-reported height and weight) with covariates including demographic variables, snoring or daytime sleepiness. Men overestimated height by 0.32 inches while women underestimated height by an average of 0.07 inches $(\mathrm{p}=0.0004)$; men and women underestimated their weights by $2.54 \mathrm{lb}$ and $7.53 \mathrm{lb}(\mathrm{p}<0.0001)$, respectively. This led to BMI being underestimated for men by $0.61 \mathrm{~kg} / \mathrm{m}^{2}$ and for women by $1.21 \mathrm{~kg} / \mathrm{m}^{2}(\mathrm{p}=0.0001)$. Age, race, residential area, and education were not significantly associated with self-reported underestimation of BMI. Neither snoring nor excessive daytime sleepiness was associated with self-reported underestimation of BMI. Multivariate linear regression analyses demonstrated that only sex was significantly associated with the difference between self-reported BMI and measured BMI.

We observed a strong relationship between the history of snoring and self-reported BMI categories and excessive daytime sleepiness. Of 403 snorers, the most commonly observed traits included being overweight $(79 \%$ based on measured BMI; 74\% based on self-reported BMI), excessive daytime sleepiness (49\%) and obesity (44\% based on measured BMI; $38 \%$ based on self-reported BMI. All yield $p$ $<0.0001$ for percentage differences between snorers and 
Table 2. The Difference ${ }^{a}$ between Mean Self-Reported and Measured BMI According to Demographic and Clinical Characteristics

\begin{tabular}{|c|c|c|c|c|}
\hline & \multicolumn{2}{|c|}{ Unadjusted $^{\mathrm{b}}$} & \multicolumn{2}{|c|}{ Adjusted $^{\mathrm{c}}$} \\
\hline & $\beta^{\mathrm{d}}$ & $95 \%$ CI for $\beta$ & $\beta$ & $95 \%$ CI for $\beta$ \\
\hline \multicolumn{5}{|l|}{ Age } \\
\hline $30-39$ & -0.37 & $-0.91,0.18$ & -0.34 & $-0.88,0.20$ \\
\hline $40-49$ & 0.10 & $-0.32,0.52$ & 0.08 & $-0.34,0.50$ \\
\hline Female & -0.61 & $-0.95,-0.26$ & -0.62 & $-0.97,-0.28$ \\
\hline Male & Reference & & Reference & \\
\hline \multicolumn{5}{|l|}{ Race } \\
\hline White & 0.18 & $-0.15,0.50$ & 0.20 & $-0.14,0.53$ \\
\hline Non-white & Reference & & Reference & \\
\hline Rural & Reference & & Reference & \\
\hline \multicolumn{5}{|l|}{ Education } \\
\hline$<$ High School & Reference & & & \\
\hline High School Graduate & -0.19 & $-0.89,0.51$ & -0.22 & $-0.92,0.48$ \\
\hline Some College or above & 0.11 & $-0.27,0.49$ & 0.14 & $-0.24,0.53$ \\
\hline \multicolumn{5}{|l|}{ Snoring Problem } \\
\hline Snorers & 0.08 & $-0.22,0.37$ & 0.11 & $-0.20,0.41$ \\
\hline Non-Snorers & Reference & & Reference & \\
\hline \multicolumn{5}{|l|}{ Excessive Daytime Sleepiness } \\
\hline Present & -0.19 & $-0.49,0.11$ & -0.18 & $-0.49,0.13$ \\
\hline
\end{tabular}

${ }^{\mathrm{a}}$ Bias of self-reported BMI= self-reported BMI - measured BMI.

${ }^{\mathrm{b}}$ Unadjusted coefficients were obtained from simple linear regression analysis.

${ }^{\mathrm{c}}$ Adjusted coefficients were obtained from multivariate linear regression analysis with all variables and adjusted for all other variables in the table.

${ }^{\mathrm{d}}$ Regression Coefficient.

non-snorers. Fig. (1) graphically depicts these differences between snoring and non-snoring individuals.

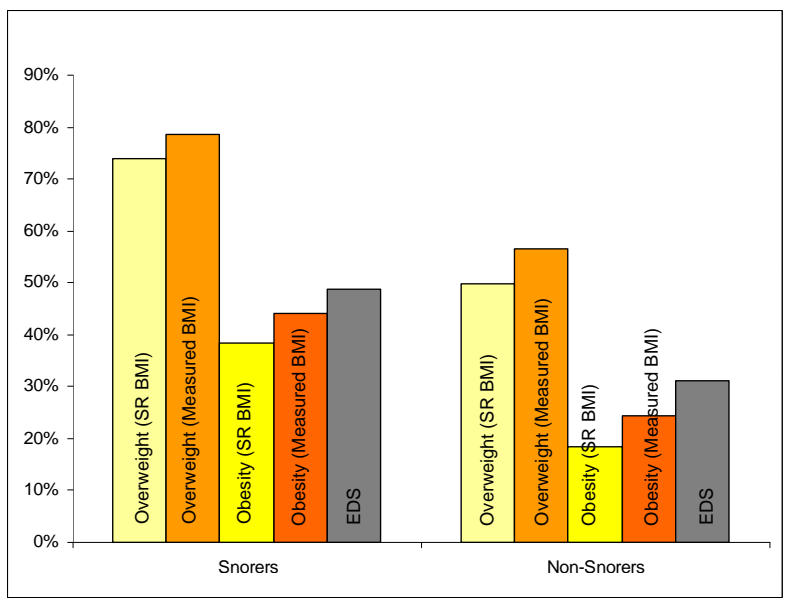

Note: $p<0.0001$ for the percentages of each outcome variables between snorers and non-snorers.

SR stands for self-reported; EDS stands for excessive daytime sleepiness.

Fig. (1). Percentages of overweight, obesity, excessive daytime sleepiness between snorers and non-snorers.

\section{Misclassification Effect of Self-Reported BMI Categories in Association with Sleep Problems}

Table 3 presents adjusted odds ratios of the probability of having sleep problems for self-reported and clinically-measured BMI categories. When self-reported BMI categories were used in the analysis with the adjustment of age, race, residential area, and education, subjects in the "Obese Class II" category were about three times more likely to snore than subjects in the normal weight category (adjusted $\mathrm{OR}=3.64$ ). When the same adjustments were made for clinicallymeasured BMI categories, subjects in the "Obese Class II" category were only twice as likely to be snorers (adjusted $\mathrm{OR}=2.97$ ). In general, for the risk of being a snorer, the odds ratios for the obese categories were slightly higher for models based on self-reported values than those based on measured values (reduction of ORs at clinic: $1 \%$ for Obese Class I; $18 \%$ for Obese Class II). There were no significant reductions in the odds ratios of excessive daytime sleepiness for self-reported BMI categories in comparison to those for measured BMI categories.

\section{DISCUSSION}

We demonstrated that self-reported and clinically-measured height and weight are highly correlated. We also 
Table 3. Adjusted Odds Ratios (OR) Relating Self-Reported and Measured BMI Categories to the Risk of Having Sleep Problems: Excessive Daytime Sleepiness and Snoring Problem

\begin{tabular}{|c|c|c|c|c|}
\hline & \multicolumn{2}{|c|}{ Based on self-reported BMI } & \multicolumn{2}{|c|}{ Based on measured BMI } \\
\hline & $\begin{array}{l}\text { Adjusted } \\
\text { OR }\end{array}$ & $\begin{array}{c}95 \% \text { CI for } \\
\text { OR }\end{array}$ & $\begin{array}{l}\text { Adjusted } \\
\text { OR }\end{array}$ & $\begin{array}{c}95 \% \text { CI for } \\
\text { OR }\end{array}$ \\
\hline \multicolumn{5}{|l|}{ Excessive Daytime Sleepiness } \\
\hline Under weight $(<18.5)$ & 0.96 & $0.34,2.77$ & 0.48 & $0.13,1.81$ \\
\hline Normal weight (18.5-24.9) & Reference & & Reference & \\
\hline Overweight (25-29.9) & 1.27 & $0.88,1.83$ & 1.26 & $0.86,1.84$ \\
\hline Obese Class I (30.0-34.9) & $1.54 *$ & $1.03,2.30$ & 1.51 & $0.99,2.31$ \\
\hline Obese Class II (35-39.9) & 1.47 & $0.78,2.78$ & 1.53 & $0.93,2.52$ \\
\hline \multicolumn{5}{|l|}{ Snorers } \\
\hline Under weight $(<18.5)$ & 0.93 & $0.31,2.83$ & 0.54 & $0.14,2.03$ \\
\hline Normal weight (18.5-24.9) & Reference & & Reference & \\
\hline Overweight (25-29.9) & $1.98 *$ & $1.37,2.85$ & $1.98^{*}$ & $1.36,2.89$ \\
\hline Obese Class I (30.0-34.9) & $4.01 *$ & $2.62,6.13$ & $3.97 *$ & $2.55,6.18$ \\
\hline Obese Class II (35-39.9) & $3.64 *$ & $1.86,7.10$ & $2.97 *$ & $1.79,4.95$ \\
\hline
\end{tabular}

Note: Models control for age, sex, race, residential area, and education. Odds ratios for underweight group should be interpreted carefully because of small sample size. $* \mathrm{p}<0.05$

observed under-reporting of weight and over-reporting of height, leading to a one-unit underestimation of BMI. Our study shows that sex influenced the extent to which weight was underestimated and height was overestimated. This concurs with findings from previous studies [22-25], in which women underestimated their weight and men overestimated their height.

We also demonstrated that errors in self-reported weight and height, and thus BMI, led to the underestimation of prevalence rates of overweight or obesity. This confirms findings from several prior studies [15, 26-32]. We now extend those findings by demonstrating that self-reported height and weight yield BMI values that detect an overweight status, with good sensitivity, high specificity, good positive and negative predictive values, and acceptable Kappa coefficients.

Our analyses reveal that the association with excessive daytime sleepiness was not overestimated when BMI categories were derived from self-reported height and weight. With regards to snoring, the association was exaggerated only for the "Obese Class II" category of self-reported BMI categories. However, this does not imply that the burden of snoring itself is overestimated. In fact, the total burden of snoring and obesity is underestimated by utilizing selfreported weight and height to estimate the case of obesity. Snoring may represent increased vulnerability for sleep apnea [33]. Results from our study suggest that the telephone survey's ascertaining prevalence rates for snoring and increased risk for sleep apnea can derive accurate assessments from self-reported data.

We recognize several limitations inherent to our study design and analyses. First, during the phone survey we did not ask "when" a person had last measured his/her height and weight. Thus, weight may have changed between the last time it was measured and our phone survey. The recall bias cannot be eliminated. In addition, an average of 117 days elapsed between the phone survey and the clinical evaluation, during which time weight may have also changed.
McAdams et al. [17] found a significant correlation between the three oldest age groups: $60-69,70-79$, and $80+$ and bias of BMI derived from self-reported weight and height. Our study did not recruit subjects from these age groups. Therefore, we cannot confirm the bias impact of selfreported BMI on the older age groups.

Excessive daytime sleepiness measured by the Epworth Sleepiness Scale was not validated with the results of the multiple sleep latency test, considered the gold standard of the diagnosis of EDS or maximum wakefulness test [34-36]. Future studies are needed to further compare the association between self-reported daytime sleepiness and BMI with objective measures. This will better determine the feasibility that phone surveys can accurately ascertain the prevalence of snoring and daytime sleepiness and their association with BMI.

\section{CONCLUSION}

Our study demonstrates that self-reported data may be a cost-effective way of obtaining information about BMI, although with limitations, because of under-reporting weight and over-reporting height in self-reported data, thus underestimating BMI and the proportion of participants with elevated BMI. Our finding of a strong association with snoring based on self-reported and clinically-measured BMI calls for further research, including studies that examine the potential benefit of integrating weight-loss/maintenance interventions into the treatment of sleep disorders.

\section{ABBREVIATIONS}

$\mathrm{BMI}=$ Body mass index

CATI $=$ Computer aided telephone interview

CFS $=$ Chronic fatigue syndrome

EDS = Excessive daytime sleepiness

$\mathrm{ESS}=$ Epworth sleepiness scale 


\section{ACKNOWLEDGEMENTS}

This study was fully funded by the US Centers for Disease Control and Prevention. The authors would like to thank Ernestina Nyarko, MPH, Kerri Timmerman, and Dr. Roumiana Boneva, of $\mathrm{CDC}$ for their reviews of the manuscript.

\section{DISCLOSURE}

The findings and conclusions in this report are those of the authors and do not necessarily represent the views of the funding agency.

\section{REFERENCES}

[1] World Health Organization. Obesity: preventing and managing the global epidemic. Technical report series no 894. Geneva, Switzerland: World Health Organization, 2000.

[2] Young T, Palta M, Dempsey J, Skatrud J, Weber S, Badr S. The occurrence of sleep-disordered breathing among middle-aged adults. N Engl J Med 1993; 328: 1230-5

[3] Zielinski J, Zgierska A, Podlodowski M, et al. Snoring and excessive daytime somnolence among Polish middle-aged adults. Eur Respir J 1999; 14: 946-50.

[4] Bearpark H, Elliott L, Grunstein R, et al. Snoring and sleep apnea: a population study in Australian men. Am J Respir Crit Care Med 1995; 151: 1459-65

[5] $\mathrm{Ng}$ TP, Seow A, Tan WC. Prevalence of snoring and sleep breathing-related disorders in Chinese, Malay and Indian adults in Singapore. Eur Respir J 1998; 12: 198-203.

[6] Ohayon, MM, Guilleminault, C, Priest RG, et al. Snoring and breathing pauses during sleep: telephone interview survey of a United Kingdom population sample. BMJ 1997; 314: 860-3.

[7] Decker MJ, Lin JM, Tabussum H, Reeves WC. Statewide Prevalence of Hypersomnolence and Sleep Related Complaints in Georgia. Am J Epidemiol 2009; 169(4): 435-43.

[8] Huang SG, Li QY. Prevalence of obstructive sleep apnea-hypopnea syndrome in Chinese adults aged over $30 \mathrm{yr}$ in Shanghai. Zhonghua Jie He He Hu Xi Za Zhi. 2003 May; 26(5): 268-72.

[9] Colten HR, Bruce M, Eds. Sleep Disorders and Sleep Deprivation: An Unmet Public Health Problem. Washington, DC: National Academies Press; 2006

[10] Strine TW, Chapman DP. Associations of frequent sleep insufficiency with health-related quality of life and health behaviors. Sleep Med 2005; 6(1): 23-7.

[11] Lamberg L. Sleep disorders, often unrecognized, complicate many physical illnesses. JAMA 2000; 284(17): 2173-5.

[12] Li QY, Huang SG, Li M, Liu JL, Wan HY. BMI is an independent risk factor for snoring in Chinese women aged over 30 years. Sleep Breath 2009; 13(3): 289-93.

[13] Bixler EO, Vgontzas AN, Lin H-M, et al. (2001). Association of excessive daytime sleepiness with sleep disordered breathing: the influence of age and BMI [abstract]. Association of Professional Sleep Societies Meeting, Chicago, IL; June 2001.

[14] Connor Gorber S, Tremblay M, Moher D, Gorber B. A comparison of direct $v s$. self-report measures for assessing height, weight and body mass index: a systematic review. Obes Rev 2007; 8: 307-26.

[15] Santillan AA, Camargo CA Jr. Body mass index and asthma among Mexican adults: the effect of using self-reported vs. measured weight and height. Int J Obes 2003; 27: 1430-3.

[16] Chiolero A, Peytremann-Bridevaux I, Paccaud F. Associations between obesity and health conditions may be overestimated if self-reported body mass index is used. Obes Rev 2007; 8: 373-4.
[17] McAdams MA, Van Dam RM, Hu FB. Comparison of Selfreported and Measured BMI as Correlates of Disease Markers in U.S. Adults. Obesity (Silver Spring) 2007; 15(1): 188-96.

[18] Shields M, Connor Gorber S, Tremblay MS. Associations between obesity and morbidity: effects of measurement methods. Obes Rev 2008; 9: 501-2

[19] Reeves WC, James FJ, Maloney E, et al. Prevalence of chronic fatigue syndrome in metropolitan, urban, and rural Georgia. Popul Health Metr 2007; 8: 5: p. 5 .

[20] Fukuda K, Straus SE, Hickie I, Sharpe M, Dobbins JG, Komaroff A. The chronic fatigue syndrome: a comprehensive approach to its definition and study. International Chronic Fatigue Syndrome Study Group. Ann Intern Med 1994; 121(12): 953-9.

[21] Johns MW. A new method for measuring daytime sleepiness: the Epworth sleepiness scale. Sleep 1991; 14: 540-5.

[22] Rowland ML. Self-reported weight and height. Am J Clin Nutr 1990; 52(6): 1125-33.

[23] Stewart AL. The reliability and validity of self-reported weight and height. J Chronic Dis 1982; 35; 295-309.

[24] Pirie P, Jacobs D, Jeffery R, Hannan P. Distortion in self-reported height and weight data. J Am Diet Assoc 1981; 78: 601-6.

[25] Kuczmarski MF, Kuczmarski RJ, Najjar M. Effects of age on validity of self-reported height, weight, and body mass index: Findings from the third National Health and Nutrition Examination Survey, 1988-1994. J Am Diet Assoc 2001; 101(1): 28-34; quiz 356.

[26] Niedhammer I, Bugel I, Bonenfant S, Goldberg M, Leclere A. Validity of self-reported weight and height in the French GAZEL cohort. Int J Obes Relat Metab Disord 2000; 24: 1111-18.

[27] Roberts RJ. Can self-reported data accurately describe the prevalence of overweight? Public Health 1995; 109: 275-84.

[28] Alvarez-Torices JC, Franch-Nadal J, Alvarez-Guisasola F, Hernandez-Mejia, Cueto-Espinar. Self-reported height and weight and prevalence of obesity. Study in a Spanish population. Int Obes Relat Metab Disord 1993; 17: 663-7.

[29] Stewart AW, Jackson RT, Ford MA, Beaglehole R Underestimation of relative weight by use of self-reported height and weight. Am J Epidemiol 1987; 125: 122-6.

[30] Nieto-Garcia FJ, Bush TL, Keyl PM. Body mass definitions of obesity: sensitivity and specificity using self-reported weight and height. Epidemiology 1990; 1: 146-52.

[31] Hill A, Roberts J. Body mass index: a comparison between selfreported and measured height and weight. J Public Health Med 1998; 20: 206-10.

[32] Aguilar-Salinas CA, Vazquez-Chavez C, Gamboa-Marrufo R, Garcia-Soto N, Rios-Gonzalez JJ, Holguin R, Vela S, Ruiz-Alvarez F, Mayagoitia S. Obesity, diabetes, hypertension, and tobacco consumption in an urban adult Mexican population. Arch Med Res 2001; 32: 446-53.

[33] Svensson M, Franklin KA, Theorell-Haglöw J, Lindberg E. Daytime sleepiness relates to snoring independent of the apneahypopnea index in women from the general population. Chest 2008; 134(9): 19-24

[34] Benbadis SR, Mascha E, Perry MC, Wolgamuth BR, Smolley LA, Dinner DS. Association between the Epworth sleepiness scale and the multiple sleep latency test in a clinical population. Ann Intern Med 1999; 130: 289-92.

[35] Johnson LC, Freeman CR, Spinweber CL, Gomez SA. 1988. The Relationship between Subjective and Objective Measures of Sleepiness. NAVAL HEALTH RESEARCH CENTER SAN DIEGO CA 07 DEC 1988, Report Number: A168502.

[36] Sangal RB, Mitlerc MM, Sangala JM. Subjective sleepiness ratings (Epworth sleepiness scale) do not reflect the same parameter of sleepiness as objective sleepiness (maintenance of wakefulness test) in patients with narcolepsy. Clin Neurophysiol 1999; 110(12): $2131-5$ 